\title{
ARTICLE
}

\section{Influencing the properties of dysprosium single-molecule magnets with phosphorus donor ligands}

Thomas Pugh', Floriana Tuna ${ }^{1,2}$, Liviu Ungur ${ }^{3}$, David Collison¹,2, Eric J.L. Mclnnes ${ }^{1,2}$, Liviu F. Chibotaru ${ }^{3} \&$ Richard A. Layfield ${ }^{1}$

Single-molecule magnets are a type of coordination compound that can retain magnetic information at low temperatures. Single-molecule magnets based on lanthanides have accounted for many important advances, including systems with very large energy barriers to reversal of the magnetization, and a di-terbium complex that displays magnetic hysteresis up to $14 \mathrm{~K}$ and shows strong coercivity. Ligand design is crucial for the development of new single-molecule magnets: organometallic chemistry presents possibilities for using unconventional ligands, particularly those with soft donor groups. Here we report dysprosium single-molecule magnets with neutral and anionic phosphorus donor ligands, and show that their properties change dramatically when varying the ligand from phosphine to phosphide to phosphinidene. A phosphide-ligated, trimetallic dysprosium single-molecule magnet relaxes via the second-excited Kramers' doublet, and, when doped into a diamagnetic matrix at the single-ion level, produces a large energy barrier of $256 \mathrm{~cm}^{-1}$ and magnetic hysteresis up to $4.4 \mathrm{~K}$.

\footnotetext{
${ }^{1}$ School of Chemistry, The University of Manchester, Oxford Road, Manchester M13 9PL, UK. ${ }^{2}$ Photon Science Institute, The University of Manchester, Oxford Road, Manchester M13 9PL, UK. ${ }^{3}$ Division of Quantum and Physical Chemistry, Katholieke Universiteit Leuven, Celestijenlaan 200F,

Leuven 3001, Belgium. Correspondence and requests for materials should be addressed to L.F.C. (email: Liviu.Chibotaru@chem.kuleuven.be) or to R.A.L. (email: Richard.Layfield@manchester.ac.uk).
} 
$\mathrm{T}$ he observation of slowly relaxing magnetization in lanthanide bis(phthalocyanine) complexes, $\mathrm{LnPc}_{2}$, has made tremendous impact in molecular magnetism ${ }^{1,2}$. Subsequently, hundreds of lanthanide single-molecule magnets (Ln-SMMs) have been reported ${ }^{3-5}$, with many examples showing very large effective energy barriers to reversal of the magnetization $\left(U_{\text {eff }}\right)^{6,7}$. Some Ln-SMMs have also been developed for applications in nanoscale devices by, for example, deposition of $\mathrm{TbPc}_{2}$ onto carbon nanostructures or metallic surfaces ${ }^{8-12}$. The $\mathrm{LnPc}_{2}$ SMMs demonstrated that very large $U_{\text {eff }}$ values can occur in monometallic complexes, and this important observation inspired the development of other monometallic Ln-SMMs with ligands such as polyoxometallates ${ }^{13}$ and organometallic ligands such as cyclo-octatetraene ${ }^{14-16}$. Organometallic synthesis offers an alternative strategy for designing Ln-SMMs owing to the diverse range of hard and soft ligands that can be accessed, and such ligands introduce new possibilities for influencing and enhancing the SMM properties ${ }^{17,18}$.

Phosphorus donor ligands provide opportunities for systematically modifying the properties of SMMs because their chemistry can be developed with neutral phosphines $\left(\mathrm{R}_{3} \mathrm{P}\right)$, mono-anionic phosphide $\left(\mathrm{R}_{2} \mathrm{P}^{-}\right)$and di-anionic phosphinidene $\left(\mathrm{RP}^{2-}\right)$ ligands, as well as the tri-anionic phosphide ligand $\left(\mathrm{P}^{3-}\right)^{19}$. Since electrostatic interactions strongly influence the electronic structure of lanthanides, the ability to synthesize compounds with similar molecular structures, but where the ligands carry different formal charges, could allow new ways of designing SMMs. Changing the organo-phosphorus ligand should also influence the exchange interactions in polymetallic systems, which is important because exchange is known to influence relaxation phenomena ${ }^{3-5}$. Phosphinidene complexes of the lanthanides are rare ${ }^{20-25}$, and, although their reactivity has been studied, their influence on $4 \mathrm{f}$ electronic structure has not. Indeed, phosphorus-ligated Ln-SMMs are unknown, hence we now target the SMM properties of dysprosium complexes with bridging phosphide and phosphinidene ligands. Here we show that organo-phosphorus chemistry can be used to influence the dynamic magnetic properties of lanthanide complexes; our observations have general implications for how main group organometallic chemistry can be used to develop new SMMs.

\section{Results}

Synthesis and structural studies. We initially targeted a primary phosphine complex of dysprosium and aimed to sequentially deprotonate the $\mathrm{P}-\mathrm{H}$ bonds. The adduct $\left[\mathrm{Cp}_{3}{ }_{3} \mathrm{Dy} \leftarrow \mathrm{PH}_{2} \mathrm{Mes}\right]$ (1-Dy) $\quad\left(\mathrm{Cp}^{\prime}=\eta^{5}-\mathrm{C}_{5} \mathrm{H}_{4} \mathrm{Me}, \quad\right.$ Mes $=$ mesityl $) \quad$ was synthesized by adding mesitylphosphine to tris(methylcyclopentadienyl) dysprosium (Fig. 1). Deprotonation of 1-Dy by ${ }^{n} \mathrm{BuLi}$ gave the trimetallic phosphide-bridged complex $\left[\left(\mathrm{Cp}_{2}{ }_{2} \mathrm{Dy}\right)\{\mu-\mathrm{P}(\mathrm{H})\right.$ Mes $\}]_{3} \cdot$ toluene (2-Dy-toluene). Deprotonation of the P-H bonds in 2-Dy by ${ }^{n} \mathrm{BuLi}$ in thf produced $\left[\mathrm{Li}\left(\mathrm{thf}_{4}\right)_{2}\right.$ $\left[\left(\mathrm{Cp}_{2}{ }_{2} \mathrm{Dy}\right)_{3}(\mu \text {-PMes })_{3} \mathrm{Li}\right] \cdot$ thf, which contains the phosphinidenebridged trimetallic complex $\left[\left(\mathrm{Cp}_{2}^{\prime}{ }_{2} \mathrm{Dy}\right)_{3}(\mu \text {-PMes })_{3} \mathrm{Li}\right]^{2-}$ (3-Dy). The analogous yttrium complexes $\left[\mathrm{Cp}_{3}^{\prime} \mathrm{Y} \leftarrow \mathrm{PH}_{2} \mathrm{Mes}\right](\mathbf{1}-\mathrm{Y})$, $\left[\left(\mathrm{Cp}_{2}^{\prime} \mathrm{Y}\right)\{\mu-\mathrm{P}(\mathrm{H}) \mathrm{Mes}\}\right]_{3} \cdot$ toluene $(2-\mathrm{Y} \cdot$ toluene $)$ and $\left[\mathrm{Li}\left(\mathrm{thf}_{4}\right]_{2}\right.$ $\left[\left(\mathrm{Cp}_{2}^{\prime} \mathrm{Y}\right)_{3}(\mu \text {-PMes })_{3} \mathrm{Li}\right] \cdot$ thf, $\quad\left[\mathrm{Li}\left(\mathrm{thf}_{4}\right]_{2}[3-\mathrm{Y}] \cdot\right.$ thf, were synthesized in an identical manner. The molecular structures of all compounds were determined by X-ray diffraction; the main features of 1-Dy, 2-Dy and 3-Dy (Fig. 1) are described below, with further details provided in Supplementary Tables 1-3, Supplementary Figs 1-10 and Supplementary Data 1-6.

Compound 1-Dy (Fig. 1) contains a dysprosium centre coordinated to three $\eta^{5}$ - $\mathrm{Cp}^{\prime}$ ligands and a $\mathrm{MesPH}_{2}$ ligand, hence the dysprosium coordination geometry can be regarded as pseudotetrahedral with respect to the centroid positions of the $\mathrm{Cp}^{\prime}$ ligands. The Dy-P bond length is 3.009(1) $\AA$ and the Dy-C bond lengths are 2.676(7)-2.744(6) $\AA$ (average $2.710 \AA$ ). To the best of our knowledge 1-Dy and 1-Y are the first crystallographically characterized rare-earth complexes of primary phosphine ligands.

Compound 2-Dy (Fig. 1) is a cyclic trimer in which the three $\left\{\mathrm{Cp}_{2}{ }_{2} \mathrm{Dy}\right\}$ units are bridged by $\mu$-(mesityl)phosphide ligands, resulting in Dy-P bond lengths of 2.926(6)-2.951(6) $\AA$. The $\mathrm{Dy}-\mathrm{Cp}^{\prime}$ bond lengths in 2-Dy fall in a broad range of 2.60(2)2.72(1) $\AA$ (average $2.64 \AA$ ). The $\left\{\mathrm{Dy}_{3} \mathrm{P}_{3}\right\}$ core of $\mathbf{2}$-Dy adopts a chair-like conformation, in which each dysprosium is coordinated by two $\mathrm{Cp}^{\prime}$ ligands, with the mesityl substituents being oriented almost perpendicular to the $\mathrm{P}_{3}$ plane. It was not possible to locate the hydrogen atoms in the structure of 2-Dy, but the P-H stretching vibrations occur in the IR spectrum at 2,358 and $2,318 \mathrm{~cm}^{-1}$ (Supplementary Fig. 8). The structure of 3-Dy also consists of a chair-like $\mathrm{Dy}_{3} \mathrm{P}_{3}$ core but with a central lithium cation, in which the $\mu_{3}$-phosphinidene ligands bridge between dysprosium and lithium. The Dy-P bonds in 3-Dy are $2.7850(15)-2.8249(15) \AA$, making them $0.13 \AA$ shorter, on average, compared with the analogous distances in 2-Dy, as expected based on stronger electrostatic bonding. The Dy-C bond lengths in 3-Dy are longer, on average, by $0.05 \AA$ compared with those in 2-Dy, suggesting that the $\mathrm{Cp}^{\prime}$ ligands in 3-Dy exhibit a degree of flexibility to accommodate the more compact $\left\{\mathrm{Dy}_{3}(\mathrm{PMes})_{3} \mathrm{Li}\right\}$ core. The lithium cation occupies a position $0.896(8) \AA$ out of the $\mathrm{P}_{3}$ plane, with Li-P bond lengths of $2.472(9), 2.477(10)$ and $2.557(8) \AA$, respectively. A mesityl orthomethyl group may interact with lithium in 3-Dy via an agostic bond; the $\operatorname{Li}(1) \cdots \mathrm{C}(45)$ distance of $2.813(11) \AA$ is markedly shorter than the $\operatorname{Li}(1) \cdots C(52)$ and $\operatorname{Li}(1) \cdots C(63)$ distances of $3.318(10)$ and 3.452(10) $\AA$, respectively. A structural feature that 3-Dy shares with other rare-earth phosphinidene complexes is the bridging coordination mode of the ligand ${ }^{20-25}$.

Magnetic property measurements. The static-field (d.c.) magnetic properties of polycrystalline 1-Dy, 2-Dy.toluene and $\left[\mathrm{Li}(\mathrm{thf})_{4}\right]_{2}[3-\mathrm{Dy}] \cdot$ thf were measured on a superconducting quantum interference device magnetometer in the temperature range of $1.8-300 \mathrm{~K}$. At $300 \mathrm{~K}$, the value of $\chi_{\mathrm{M}} T(T)$ for 1-Dy, where $\chi_{\mathrm{M}}$ is the molar magnetic susceptibility, is $12.85 \mathrm{~cm}^{3} \mathrm{~K}$ $\mathrm{mol}^{-1}$; cooling the sample to $1.8 \mathrm{~K}$ produces a gradual decrease in $\chi_{\mathrm{M}} T$, such that a value of $7.93 \mathrm{~cm}^{3} \mathrm{~K} \mathrm{~mol}^{-1}$ is eventually reached (Supplementary Fig. 11). The field $(H)$ dependence of the magnetization $(M)$ for 1-Dy reveals a steep increase up to $1 \mathrm{~T}$, followed by a more gradual increase up to $7 \mathrm{~T}$, where the value of $M=5.09 \mu_{\mathrm{B}}$ is consistent with a single $\mathrm{Dy}^{3+}$ ion with a ${ }^{6} \mathrm{H}_{15 / 2}$ ground state (Supplementary Fig. 12). The $\chi_{M} T$ values for 2-Dy · toluene and $\left[\mathrm{Li}(\mathrm{thf})_{4}\right]_{2}[3-\mathrm{Dy}] \cdot$ thf at $300 \mathrm{~K}$ are 40.08 and $42.41 \mathrm{~cm}^{3} \mathrm{~K} \mathrm{~mol}^{-1}$, respectively, both of which are close to the predicted values for three uncoupled $\mathrm{Dy}^{3+}$ centres $^{26}$; both $\chi_{\mathrm{M}} T$ values decrease gradually down to about $50 \mathrm{~K}$, and then more rapidly to reach 17.81 and $19.47 \mathrm{~cm}^{3} \mathrm{~K} \mathrm{~mol}^{-1}$, respectively, at $1.8 \mathrm{~K}$ (Supplementary Fig. 11). For 2-Dy-toluene and $\left[\mathrm{Li}\left(\mathrm{thf}_{4}\right]_{2}[3-\mathrm{Dy}] \cdot\right.$ thf, the magnetization at $1.8 \mathrm{~K}$ increases rapidly up to about $2 \mathrm{~T}$, before following a more gradual increase up to $7 \mathrm{~T}$, where values of $M=16.10$ and $16.13 \mu_{\mathrm{B}}$ are reached. The $M(H)$ data for the two trimetallic complexes are consistent with the expected value for three uncoupled $\mathrm{Dy}^{3+}$ ions (Supplementary Fig. 12).

The dynamic (a.c.) magnetic susceptibility properties of the three dysprosium compounds show much greater variation. For 1-Dy, a maximum was observed in the plot of the out-of-phase magnetic susceptibility $\left(\chi^{\prime \prime}\right)$ versus a.c. frequency $(v)$ at $1.8 \mathrm{~K}$, but not at higher temperatures up to the maximum frequency that can be achieved with our susceptometer (Supplementary Fig. 13). 
a

$3\left[\mathrm{Cp}_{3}^{\prime} \mathrm{M}\right]+3 \mathrm{MesPH}_{2}$

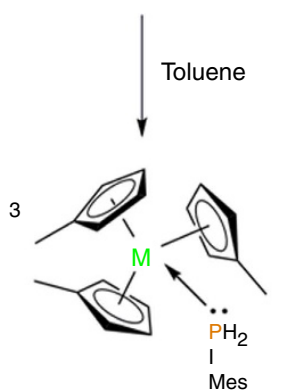

$3^{n} \mathrm{BuLi} \mid-3^{n} \mathrm{BuH}$

toluene

$-3 \mathrm{Cp}$ 'Li
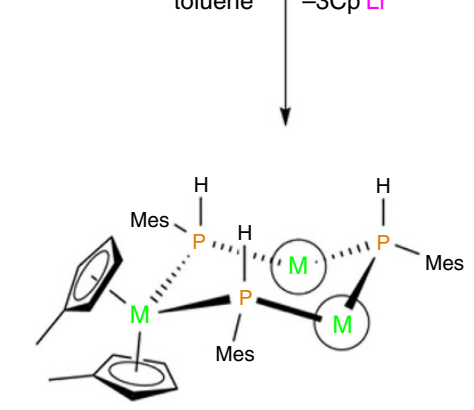

$3^{n}$ BuLi, thf

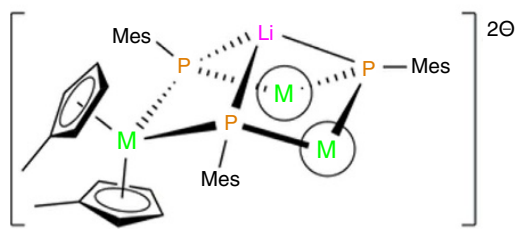

$2\left[\mathrm{Li}(\text { thf })_{4}\right]^{\oplus}$ b

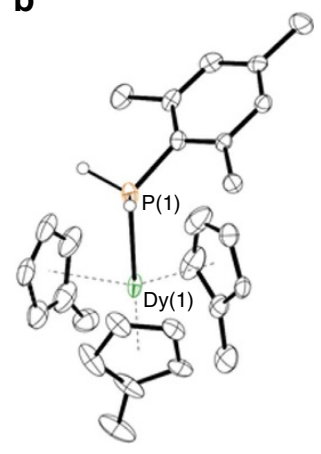

C

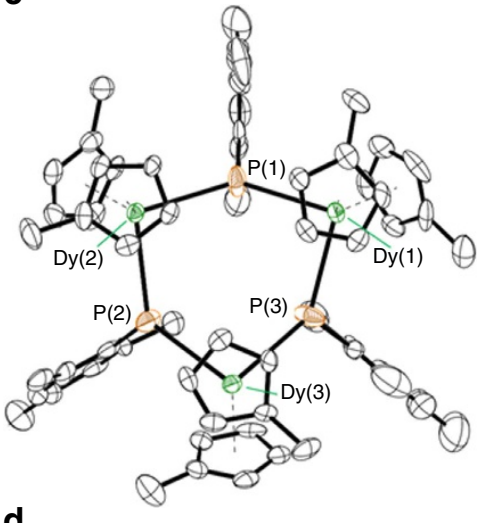

d

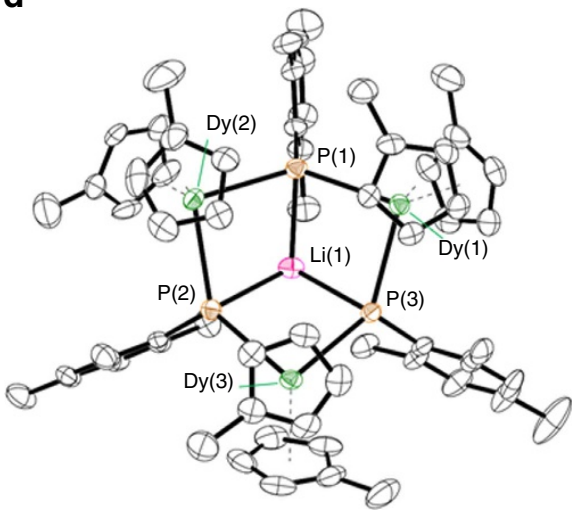

Figure 1 | Synthesis and molecular structures. (a) Synthesis of the yttrium-phosphorus and dysprosium-phosphorus complexes. (b) Thermal ellipsoid representation of the molecular structure of 1-Dy. (c) Molecular structure of 2-Dy. (d) Molecular structure of 3-Dy. Hydrogen atoms are omitted for clarity.

These data indicate rapid relaxation of the magnetization in 1-Dy above $1.8 \mathrm{~K}$. In contrast, in zero applied d.c. field, the $\chi^{\prime \prime}(v)$ isotherms of 2-Dy toluene have well-defined frequency-dependent maxima up to $31 \mathrm{~K}$, which demonstrates SMM behaviour with a large thermal energy barrier (Fig. 2 and Supplementary Figs 14 and 15). The energy barrier for the thermal relaxation in 2-Dy toluene was extracted using the relationship $\tau=\tau_{0}$ exp $\left(U_{\text {eff }} / k_{\mathrm{B}} T\right)$, which gave $U_{\text {eff }}=210(6) \mathrm{cm}^{-1}$, with a pre-exponential factor of $\tau_{0}=6.53 \times 10^{-9} \mathrm{~s}$. Below about $20 \mathrm{~K}$, the dependence of $\ln \tau$ on $1 / T$ weakens and deviates from linearity, but does not become fully temperature independent even at $1.8 \mathrm{~K}$ (Fig. 2). This observation implies that other relaxation mechanisms, such as quantum tunnelling of the magnetization and Raman or direct relaxation, occur concurrently with the thermal relaxation process at lower temperatures. In contrast, the $\chi^{\prime \prime}(v)$ isotherms in $\left[\mathrm{Li}(\mathrm{thf})_{4}\right]_{2}[3-\mathrm{Dy}] \cdot$ thf only show maxima below $3.6 \mathrm{~K}$, and the position of the maximum moves only slightly as the temperature is reduced to $1.8 \mathrm{~K}$ (Supplementary Figs 16 and 17). The plot of $\ln$ $\tau$ versus $1 / T$ for the phosphinidene-bridged complex produces an anisotropy barrier of $U_{\text {eff }}=13(1) \mathrm{cm}^{-1}\left(\tau_{0}=7.75 \times 10^{-7} \mathrm{~s}\right)$, that is, more than an order of magnitude smaller than in phosphidebridged 2-Dy $\cdot$ toluene.

To examine the influence of dysprosium-dysprosium interactions, magnetically dilute samples of $5 \%$ dysprosium in $\mathbf{2}-\mathbf{Y} \cdot$ toluene and $\left[\mathrm{Li}(\mathrm{thf})_{4}\right]_{2}[3-\mathrm{Y}] \cdot$ thf were prepared; dilution was achieved by mixing 1-Y and 1-Dy in a 20:1 ratio and then synthesizing the complexes according to Fig. 1. This enabled isolation of crystalline samples of $2-Y_{2} \mathbf{D y} \cdot$ toluene in a matrix of $\mathbf{2}-\mathbf{Y}$. toluene and, similarly, $\left[\mathrm{Li}(\text { thf })_{4}\right]_{2}\left[\mathbf{3}-\mathbf{Y}_{\mathbf{2}} \mathbf{D y}\right] \cdot$ thf in a matrix of $\left[\mathrm{Li}(\mathrm{thf})_{4}\right]_{2}[3-\mathrm{Y}] \cdot$ thf. For both doped trimetallic compounds the a.c. susceptibility data are similar to those measured for the pure samples (Fig. 2, Supplementary Figs 18 and 19), that is, the phosphinidene-bridged complex shows very weak SMM behaviour, while $2-Y_{2} \mathbf{D y} \cdot$ toluene is an SMM but with an increased 

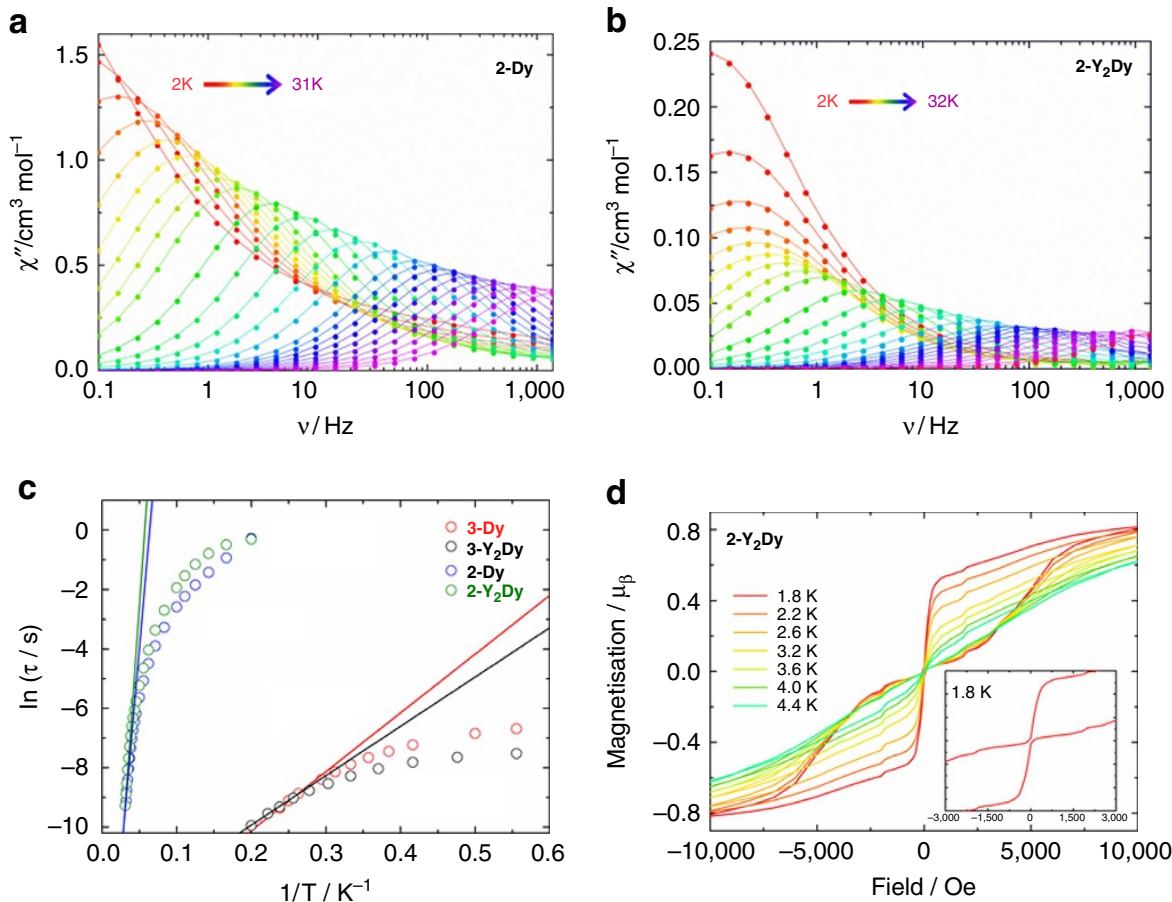

Figure 2 | Magnetic properties of selected dysprosium-phosphorus compounds. (a) $\chi^{\prime \prime}(v)$ for 2-Dy · toluene in the temperature range of 2-31 $\mathrm{K}$ with an a.c. field of $1.55 \mathrm{Oe}$ and zero d.c. field. (b) $\chi^{\prime \prime}(v)$ for $\mathbf{2}-\mathbf{Y}_{\mathbf{2}} \mathbf{D} \mathbf{y}$ - toluene in the temperature range of $2-32 \mathrm{~K}$ with an a.c. field of $1.55 \mathrm{Oe}$ and zero d.c. field. (c) Arrhenius plots for $\mathbf{2}-\mathbf{D y}$ - toluene (blue circles), $\mathbf{2}-\mathbf{Y}_{\mathbf{2}} \mathbf{D} \mathbf{D} \cdot$ toluene (green circles), $\left[\mathrm{Li}\left(\mathrm{thf}_{4}\right)_{4}\right]_{2}[\mathbf{3}-\mathbf{D} \mathbf{D}] \cdot$ thf (red circles) and $\left.[\mathrm{Li} \text { (thf) }]_{4}\right]_{2}\left[\mathbf{3}-\mathbf{Y}_{\mathbf{2}} \mathbf{D} \mathbf{D y}\right] \cdot$ toluene (black circles). The solid lines represent data fits in the range of $27-31 \mathrm{~K}$ for $\mathbf{2}-\mathbf{D} \mathbf{y} \cdot$ toluene, $28-32 \mathrm{~K}$ for $\mathbf{2}-\mathbf{Y}_{\mathbf{2}} \mathbf{D} \mathbf{D} \cdot$ toluene, 3.8-4.2 $\mathrm{K}$ for $\left[\mathrm{Li}(\text { thf })_{4}\right]_{2}[\mathbf{3}-\mathbf{D} \mathbf{D}] \cdot$ thf and 3.9-5 K for $\left[\mathrm{Li}(\text { thf })_{4}\right]_{2}\left[\mathbf{3}-\mathbf{Y}_{\mathbf{2}} \mathbf{D} \mathbf{D}\right] \cdot$ thf. (d) $M(H)$ loops for $\mathbf{2}-\mathbf{Y}_{\mathbf{2}} \mathbf{D} \mathbf{y}$ 1.8-4.4 K with a sweep rate of $2.6 \mathrm{mTs}^{-1}$.

anisotropy barrier of $U_{\text {eff }}=256(6) \mathrm{cm}^{-1}$. There is a much clearer and more important difference in the $M(H)$ hysteresis measurements for the undiluted and diluted systems. For 2-Dy - toluene, the $M(H)$ curve at $1.8 \mathrm{~K}$ (Supplementary Fig. 20) shows very narrow hysteresis, while hysteresis is found for $2-\mathbf{Y}_{2} \mathbf{D y} \cdot$ toluene up to $4.4 \mathrm{~K}$, with significant widening of the butterfly-shaped loops as the temperature is lowered (Fig. 2). The coercive field for $2-Y_{2} \mathrm{Dy} \cdot$ toluene at $1.8 \mathrm{~K}$ is estimated to be $H_{\mathrm{c}} \approx 300 \mathrm{Oe}$, with a small remanent magnetization of $M_{\mathrm{r}} \approx 0.03 \mu_{\mathrm{B}}$ (sweep rate $2.6 \mathrm{mT} \mathrm{s}^{-1}$ ). The $M(H)$ plot for $2-\mathbf{Y}_{2} \mathbf{D y} \cdot$ toluene also shows steps at $H \approx \pm 1,800 \mathrm{Oe}$, which is probably due to small amounts of the partially doped di-dysprosium complex 2-YDy. In low magnetic fields, the ground state of $\mathbf{2}-\mathbf{Y D y}_{\mathbf{2}}$ is defined by antiferromagnetic exchange, but above a certain field strength the ground state changes to ferromagnetic and has a greater magnetic moment, hence the steps in the $M(H)$ curves. The precise field at which the steps are found is consistent with the calculated exchange spectrum from 2-Dy (see below). A feature similar to this has been observed in magnetic dilution studies of di-dysprosium $\mathrm{SMMs}^{27,28}$. As $U_{\text {eff }}$ is similar for 2-Dy-toluene and $2-Y_{2} \mathrm{Dy} \cdot$ toluene, the difference in hysteresis must be due to non-thermal relaxation being more important in the undiluted compound.

Quantum chemical calculations. Further insight into the electronic structure and the magnetic blocking in the dysprosium complexes was obtained using $a b$ initio quantum chemical calculations. Current $a b$ initio methods are not suitable for treating several magnetic $4 \mathrm{f}$ centres simultaneously; therefore, in the case of 2-Dy and 3-Dy appropriate fragmentation was imposed, hence $\mathrm{Lu}^{3+}$ was used in place of neighbouring Dy ${ }^{3+}$ (Supplementary Figs 22-24). All calculations on mono-dysprosium fragments
Table 1 | Calculated low-lying energy $\left(\mathrm{cm}^{-1}\right)$ spectrum of individual $\mathrm{Dy}^{3}+$ sites in 1-Dy, 2-Dy and 3-Dy.

\begin{tabular}{|c|c|c|c|c|c|c|c|}
\hline \multirow[t]{2}{*}{ KD } & \multirow[t]{2}{*}{ 1-Dy } & \multicolumn{3}{|c|}{ 2-Dy } & \multicolumn{3}{|c|}{ 3-Dy } \\
\hline & & Dy1 & Dy2 & Dy3 & Dy1 & Dy2 & Dy3 \\
\hline 1 & 0.0 & 0.0 & 0.0 & 0.0 & 0.0 & 0.0 & 0.0 \\
\hline 2 & 45.2 & 126.7 & 134.2 & 135.0 & 63.8 & 69.5 & 100.7 \\
\hline 3 & 98.7 & 277.3 & 296.8 & 297.8 & 77.4 & 88.8 & 104.4 \\
\hline 4 & 287.1 & 345.8 & 320.9 & 334.4 & 116.2 & 108.5 & 132.9 \\
\hline 5 & 339.5 & 362.7 & 388.7 & 381.0 & 136.0 & 148.5 & 150.2 \\
\hline 6 & 391.7 & 402.8 & 431.0 & 419.0 & 160.6 & 160.9 & 181.1 \\
\hline 7 & 452.5 & 433.6 & 499.2 & 478.0 & 194.0 & 187.1 & 217.2 \\
\hline 8 & 583.9 & 551.7 & 675.6 & 637.8 & 232.1 & 271.2 & 290.6 \\
\hline
\end{tabular}

were performed with MOLCAS ${ }^{29}$ and were of CASSCF/RASSI/ SINGLE_ANISO type (Supplementary Tables $4-9)^{30}$. Tables 1 and 2 show the energy spectrum and the magnetic anisotropy of the lowest Kramers' doublets on individual dysprosium sites of the three compounds.

For the phosphine adduct 1-Dy, the lack of SMM properties is consistent with the absence of strong magnetic axiality of the ground and excited doublets (Table 2). The presence of large $g_{x, y}$ values in the ground state enables fast quantum tunnelling between states with opposite magnetization, destroying any potential blocking of the magnetization ${ }^{31,32}$. This can be rationalized in terms of the molecular and electronic structure of 1-Dy, where the main magnetic axis $\left(g_{\mathrm{z}}\right)$ lies in a plane defined by three $\mathrm{Cp}^{\prime}$ ligands (Supplementary Fig. 26). The electrostatic potential of the ligand field is dominated by the anionic $\mathrm{Cp}^{\prime}$ ligands, which are much closer to dysprosium (average $\mathrm{Dy}-\mathrm{C}=2.710 \AA$ ) than the charge- 


\begin{tabular}{|c|c|c|c|c|c|c|c|}
\hline$\frac{\mathbf{K D}}{1}$ & 1-Dy & \multicolumn{3}{|c|}{ 2-Dy } & \multicolumn{3}{|c|}{ 3-Dy } \\
\hline$g_{\mathrm{x}}$ & 0.886 & $3.39 \times 10^{-4}$ & $1.97 \times 10^{-3}$ & $2.93 \times 10^{-4}$ & $4.23 \times 10^{-3}$ & $1.49 \times 10^{-2}$ & $5.04 \times 10^{-3}$ \\
\hline$g_{y}$ & 5.417 & $4.76 \times 10^{-4}$ & $3.67 \times 10^{-3}$ & $5.08 \times 10^{-4}$ & $8.37 \times 10^{-3}$ & $2.90 \times 10^{-2}$ & $8.07 \times 10^{-3}$ \\
\hline$g_{z}$ & 15.016 & 19.43 & 19.30 & 19.46 & 19.49 & 19.24 & 19.68 \\
\hline$g_{\mathrm{x}}$ & 2.598 & $1.16 \times 10^{-3}$ & $2.13 \times 10^{-2}$ & $3.06 \times 10^{-3}$ & 0.86 & 0.16 & 1.23 \\
\hline$g_{y}$ & 3.359 & $1.56 \times 10^{-3}$ & $2.27 \times 10^{-2}$ & $3.24 \times 10^{-3}$ & 1.09 & 0.26 & 2.57 \\
\hline$g_{z}$ & 6.358 & 17.05 & 16.85 & 16.97 & 17.50 & 18.60 & 14.52 \\
\hline$\angle\left(g_{z 1}, g_{z 2}\right)^{\star}$ & $52.0^{\circ}$ & $4.2^{\circ}$ & $6.7^{\circ}$ & $2.3^{\circ}$ & $60.2^{\circ}$ & $43.4^{\circ}$ & $49.7^{\circ}$ \\
\hline$\angle\left(g_{z 1}, \mathrm{Dy}_{3}\right)^{\dagger}$ & & $70.4^{\circ}$ & $72.1^{\circ}$ & $69.3^{\circ}$ & $81.2^{\circ}$ & $82.7^{\circ}$ & $81.8^{\circ}$ \\
\hline
\end{tabular}

neutral phosphine ligand ( $\mathrm{Dy}-\mathrm{P}=3.009 \AA$ ). Strong equatorial ligand fields are known to diminish magnetization blocking in $\mathrm{Dy}^{3+}$ complexes $^{14,33}$, hence the weak SMM properties of 1-Dy.

The dysprosium sites in 2-Dy display the strongest magnetic axiality in the ground and excited doublet states, which is combined with the largest splitting of the eight Kramers' doublets within the ground $J=15 / 2$ manifold of the three systems investigated. The local main magnetic axes $\left(g_{\mathrm{z}}\right)$ in 2-Dy make angles of $69^{\circ}-72^{\circ}$ with the $\mathrm{Dy}_{3}$ plane (Fig. 3, Table 2). This direction of the magnetization axis on each dysprosium is the result of the strong axial ligand field generated by the two $\mathrm{Cp}^{\prime}$ ligands, which are closer to dysprosium (average $\mathrm{Dy}-\mathrm{C}=2.64 \AA$ ) than phosphorus (average $\mathrm{Dy}-\mathrm{P}=2.934 \AA$ ), consistent with the electronic properties of closely related metallocene-based SMMs ${ }^{34-37}$. The very small angles between the anisotropy axes in the ground and first-excited Kramers' doublets in 2-Dy, combined with their strong magnetic axiality (Table 2 and Fig. 3), are necessary conditions for magnetic relaxation via the second-excited doublet states at higher temperatures ${ }^{6,14,38}$. The calculated energy of the second-excited state (Table 1) gives a reasonable agreement with experiment, being higher than the extracted $U_{\text {eff }}$ value by about $20-40 \mathrm{~cm}^{-1}$. Whereas lanthanide SMMs can be designed with ligand environments that promote strongly axial magnetic ground states, targeting SMMs with very large $U_{\text {eff }}$ values also requires the excited states to possess main magnetic axes that lie close to co-linear with the ground state, which is challenging. In the case of 2-Dy, the electronic and molecular structures of the individual $\left\{\mathrm{Cp}_{2}^{\prime} \mathrm{Dy}\{\mu-\mathrm{P}(\mathrm{H}) \mathrm{Mes}\}\right.$ units appear to fit the requirements for a dysprosium SMM in which the ground $\left|m_{\mathrm{J}}\right|=15 / 2$ states and $\left|m_{\mathrm{J}}\right|=13 / 2$ excited states are indeed co-linear. The strong magnetic axiality of the dysprosium sites is expected to be preserved in the diluted compound $\mathbf{Y}_{\mathbf{2}} \mathbf{D} \mathbf{y}$, which explains the detection of magnetic hysteresis in this system (Fig. 2).

The dysprosium sites in 3-Dy display a much smaller total splitting of the ground $J=15 / 2$ manifold compared with 2-Dy (Table 1). The different splittings are presumably influenced by subtle differences in the structures of the two complexes, that is, greater distances to the $\mathrm{Cp}^{\prime}$ ligands (by 0.03-0.09 $\AA$ ) in 3-Dy, reduced $C \mathrm{p}_{\text {cent }}-\mathrm{Dy}-\mathrm{C} \mathrm{p}_{\text {cent }}$ angles (by $\sim 3.4^{\circ}$ ) and shorter $\mathrm{Dy}-\mathrm{P}$ bonds (by $0.10-0.16 \AA$ ) together with their greater formal charge. Indeed, the calculated charges on the phosphinidene donor atoms in 3-Dy range from -0.6 to -0.9 , compared with the calculated charges of -0.1 to -0.3 on the phosphide donors in $2-\mathrm{Dy}^{39}$.
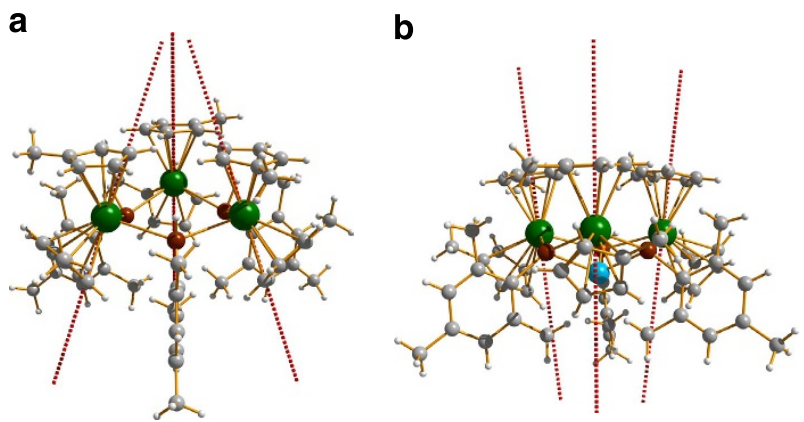

Figure 3 | Orientation of the main magnetic axes in the ground Kramers' doublets. (a) For 2-Dy. (b) For 3-Dy. The magnetic axes are represented as dashed red lines. The dysprosium centres are represented as green spheres and the phosphorus atoms as orange spheres.

The closely located phosphinidene ligands and their charge produce a much stronger equatorial ligand field, which counteracts the axial field arising from the $\mathrm{Cp}^{\prime}$ ligands. Although the ground Kramers' doublet is still characterized by $\left|m_{\mathrm{J}}\right|=15 / 2$, the enhanced equatorial ligand field stabilizes other $m_{\mathrm{J}}$ states and enables greater mixing in 3-Dy relative to 2-Dy. This is reflected in weaker magnetic axiality of the ground state in 3-Dy. Moreover, the first-excited doublets of 3-Dy feature relatively large transverse $g$-values $\left(g_{\mathrm{x}}\right.$ and $g_{\mathrm{y}}$ in Table 2$)$, which, combined with the large angles with the ground-state main magnetic axis, leads to fast magnetic relaxation through this doublet at high temperatures.

The $a b$ initio results for the individual metal sites were used to compute the exchange spectrum and the magnetic properties of the trimetallic complexes using the POLY_ANISO program ${ }^{40,41}$. The fitted Lines exchange parameters are given in Supplementary Table 10. The macroscopic magnetic properties were further computed on the basis of the exchange spectrum. Given the strong magnetic axiality of the ground-state Kramers' doublets on the dysprosium sites, the magnetic interaction (exchange + dipolar) between them can be described by the non-collinear Ising Hamiltonian in equation 1.

$$
\hat{\mathrm{H}}_{\mathrm{exch}}=-J_{12} \hat{\tilde{\tilde{s}}}_{z 1} \hat{\tilde{s}}_{z 2}-J_{23} \hat{\tilde{s}}_{z 2} \hat{\tilde{\tilde{s}}}_{z 3}-J_{13} \hat{\tilde{\tilde{s}}}_{z 1} \hat{\tilde{s}}_{z 3},
$$

In equation $1, J_{\mathrm{ij}}=J_{\mathrm{ij}}^{\text {exch }}+J_{\mathrm{ij}}^{\mathrm{dip}}$ is the parameter of the total magnetic interaction between metal sites $i$ and $j$, including the dipolar and exchange contributions (Supplementary Table 10), $\hat{\tilde{s}}_{z i}$ 
is the projection of the pseudo-spin $1 / 2$, describing the ground Kramers' doublet on the $i$-th dysprosium site, on the corresponding main magnetic axis $z_{\mathrm{i}}$. The exchange and magnetic dipolar interactions between dysprosium sites in both compounds are antiferromagnetic. For the calculated directions of the main anisotropy axes on the dysprosium sites in 2-Dy and 3-Dy (Fig. 3), the antiferromagnetic exchange and dipolar interactions will stabilize the sixfold degenerate (that is, three Kramers' doublets), frustrated exchange Kramers' doublets (Supplementary Table 10). In a frustrated manifold, magnetization blocking of the exchange type is suppressed because all its states can be accessed by reversal of individual magnetic moments on Dy sites (illustrated for 2-Dy in Fig. 4$)^{42}$. As a consequence, a quantum tunnelling of the magnetization process as fast as those in single-ion complexes is expected. Under these circumstances, the magnetization blocking is expected to arise from individual dysprosium ions. Actually, the magnetic moment reversal on the individual dysprosium ions in the trimetallic compounds 2-Dy and 3-Dy is expected to be faster than in the isostructural complexes containing one single dysprosium, that is, $2-\mathbf{Y}_{2} \mathbf{D y}$ and $3-\mathbf{Y}_{2} \mathbf{D y}$, because in a frustrated compound the presence of nearest neighbour magnetic sites will enhance the magnetization reversal rate on each magnetic ion ${ }^{42,43}$. This is the reason for the clearly enhanced blocking of magnetization and the observation of pronounced hysteresis in in $2-\mathbf{Y}_{2}$ Dy (Fig. 2) ${ }^{42}$.

Magnetization blocking of the exchange type is expected to be efficient only at temperatures not exceeding the exchange splitting, which is the case here because the magnetic coupling constant between two dysprosium ions in 2-Dy is $\sim 4 \mathrm{~cm}^{-1}$ (Supplementary Table 10). The calculated exchange splitting for 2-Dy also provides insight into the steps observed in the $M(H)$

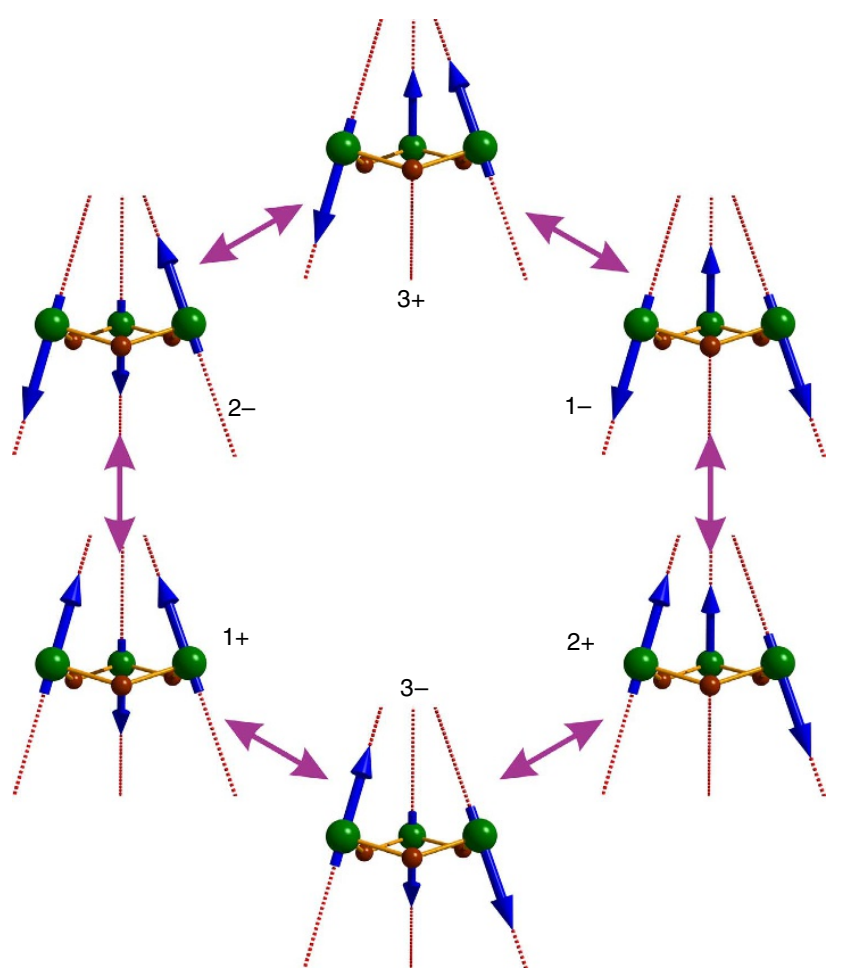

Figure 4 | The three low-lying quasidegenerate exchange levels of 2-Dy. The six magnetic eigenstates are related via flips of magnetic moments (blue arrows) on the individual dysprosium sites. The + and - symbols represent time-reversal components corresponding to one exchange Kramers' doublet. profile for $2-\mathbf{Y}_{2} \mathbf{D y}$ : the exchange splitting in partially doped 2-YDy 2 will be about $2 \mathrm{~cm}^{-1}$, that is, $\sim 2,000 \mathrm{Oe}$, which is in good agreement with the experimentally observed steps at 1,800 Oe.

\section{Discussion}

We have reported a new route to rare-earth complexes of phosphide and phosphinidene ligands. The a.c. susceptibility measurements on phosphide-ligated SMM 2-Dy reveal a large effective energy barrier of $U_{\text {eff }}=210(5) \mathrm{cm}^{-1}$, increasing to $256(6) \mathrm{cm}^{-1}$ on dilution in $2-Y_{2}$ Dy. In contrast, 1-Dy and phosphinidene-ligated $\left[\mathrm{Li}(\mathrm{thf})_{4}\right]_{2}[3-\mathrm{Dy}]$, and their diluted analogues, do not show prominent SMM properties. Theoretical studies of 2-Dy and 3-Dy identify that the main magnetic axes on the $\mathrm{Dy}^{3+}$ ions in the ground Kramers' doublet have similar orientations approximately perpendicular to the $\mathrm{Dy}_{3}$ plane; even allowing for small differences in the axis orientations (of about $10^{\circ}$ ), the phosphorus atoms occupy equatorial positions, hence the greater electrostatic demands of the phosphinidene ligands diminish the axiality. In 2-Dy, the thermal magnetic relaxation proceeds via the second-excited Kramers' doublet owing to the near-collinearity of the magnetization axes in the ground- and first-excited doublets. The reduced axiality of the first-excited Kramers' doublet in 3-Dy, combined with different orientations of the main magnetic axes in the ground- and first-excited doublets, explains the weak magnetic blocking in this system.

The field dependence of the magnetization for 2-Dy shows very narrow hysteresis at $1.8 \mathrm{~K}$, however butterfly-shaped hysteresis was found up to $4.4 \mathrm{~K}$ for $2-\mathrm{Y}_{2} \mathrm{Dy}$. The properties of undiluted 2-Dy can be explained in terms of the exchange coupling and frustrated ground state, which enable rapid reversal of the magnetic moments on the individual dysprosium sites. The absence of exchange coupling in $2-\mathbf{Y}_{2}$ Dy allows more prominent blocking of the magnetization.

Substantial changes to SMM properties can be achieved using a bottom-up approach in which dysprosium phosphide complexes are converted into their phosphinidene analogues. The general features of the chemistry and the electronic structure suggest that exploring other lanthanides and other unconventional ligands in place of phosphorus should enable further enhancements in the SMM behaviour.

\section{Methods}

General synthesis considerations. All manipulations were performed under an atmosphere of dry, oxygen-free argon, using either standard Schlenk techniques or an argon-filled glove box. Toluene and thf, and their deuterated analogues for NMR spectroscopy, were dried by refluxing over potassium and collected by distillation. All solvents were stored over activated $4 \AA$ molecular sieves and freezethaw degassed before use. Anhydrous rare-earth chlorides (99.99\% purity) were purchased from Strem Chemicals. $n$-Butyllithium (1.6 M in hexanes), phosphorus(III) chloride, lithium aluminium hydride, mesitylmagnesium bromide (1.0 M in thf) and di-methylcyclopentadiene (90\%) were purchased from Sigma-Aldrich. Mesitylphosphine ${ }^{44}$, the sodium salt of methylcyclopentadienide ${ }^{45}$, and rare-earth tris(methylcyclopentadienide) complexes were synthesised according to the literature procedures ${ }^{46}$. Elemental analyses were carried out by Mr Stephen Boyer at London Metropolitan University, UK

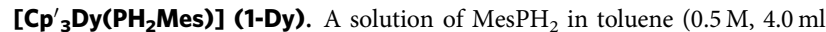
$2.0 \mathrm{mmol})$ was added to a solution of $\mathrm{Cp}_{3}^{\prime} \mathrm{Dy}(0.80 \mathrm{~g}, 2.0 \mathrm{mmol})$ in toluene $(4 \mathrm{ml})$ at room temperature, and the reaction mixture was stirred for $1 \mathrm{~h}$. The resulting pale yellow solution was filtered, concentrated and stored at $-30{ }^{\circ} \mathrm{C}$ overnight, which resulted in the formation of 1-Dy as colourless crystals $(0.92 \mathrm{~g}, 83 \%$ isolated yield). Elemental analysis, found per percentage (calculated per percentage) for 1-Dy: C, 58.62 (58.74); H, 6.28 (6.21).

[C $\mathbf{p}_{\mathbf{3}}^{\prime} \mathbf{Y}\left(\mathbf{P H}_{\mathbf{2}} \mathbf{M e s}\right) \mathbf{\text { (1-Y)}}$. The synthesis of $\mathbf{1 - Y}$ was accomplished using the procedure described above for 1-Dy, with the following amounts: $\mathrm{MesPH}_{2}(0.5 \mathrm{M}$, $4.0 \mathrm{ml}, 2.0 \mathrm{mmol}), \mathrm{Cp}^{\prime}{ }_{3} \mathrm{Y}(0.65 \mathrm{~g}, 2.0 \mathrm{mmol})$ and toluene $(4 \mathrm{ml})$. 1-Y formed as colourless crystals $(0.71 \mathrm{~g}, 75 \%$ isolated yield). Elemental analysis, found percentage (calculated percentage) for 1-Y: C, 67.39 (67.78); H, 7.21 (7.16). ${ }^{1} \mathrm{H}$ NMR (benzene- $\mathrm{D}_{6}, 298.15 \mathrm{~K}, \delta /$ p.p.m.): 6.65 (s, $2 \mathrm{H}$, mesityl $\left.\mathrm{CH}\right) ; 5.85,5.72(\mathrm{~m}, 12 \mathrm{H}$, 
$\left.\mathrm{C}_{5} \mathrm{H}_{4} \mathrm{CH}_{3}\right) ; 3.86\left(\mathrm{~d}, 2 \mathrm{H}, \mathrm{PH}_{2},{ }^{1} \mathrm{~J}_{\mathrm{P}-\mathrm{H}}=251 \mathrm{~Hz}\right) ; 2.16\left(\mathrm{~s}, 6 \mathrm{H}\right.$, ortho $\left.\mathrm{CH}_{3}\right) ; 2.10$ $\left(\mathrm{s}, \overline{9} \mathrm{H}, \mathrm{Cp}^{\prime} \mathrm{CH}_{3}\right) ; 2.03\left(\mathrm{~s}, 3 \mathrm{H}\right.$, para $\left.\mathrm{CH}_{3}\right) .{ }^{31} \mathrm{P}$ NMR (benzene- $\mathrm{D}_{6}, 298.15 \mathrm{~K}, \delta /$ p.p.m.): -130.80

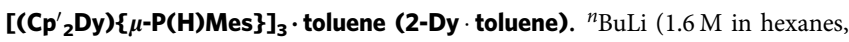
$0.66 \mathrm{ml}, 1.06 \mathrm{mmol})$ was added to a solution of 1-Dy $(0.55 \mathrm{~g}, 1.06 \mathrm{mmol})$ in toluene $(20 \mathrm{ml})$ at $-78^{\circ} \mathrm{C}$, and the reaction mixture was stirred for $1 \mathrm{~h}$. The reaction was then slowly warmed to room temperature overnight, after which time a pale yellow solution and a precipitate had formed. The resulting pale yellow solution was filtered and concentrated, which resulted in the formation of a yellow precipitate. The precipitate was re-dissolved and the solution stored at $-30^{\circ} \mathrm{C}$ overnight, which resulted in the formation of 2-Dy · toluene as colourless crystalline blocks $(0.34 \mathrm{~g}, 63 \%)$. Elemental analysis, found percentage (calculated percentage) for 2-Dy·toluene: C, 55.63 (55.76); H, 5.83 (5.75).

$\left[\left(\mathrm{Cp}_{2}^{\prime} \mathbf{Y}\right)\{\boldsymbol{\mu}-\mathrm{P}(\mathrm{H}) \mathbf{M e s}\}\right]_{3} \cdot$ toluene (2-Y $\cdot$ toluene). The synthesis of $\mathbf{2}-\mathrm{Y} \cdot$ toluene was accomplished using the procedure described above for 2-Dy $\cdot$ toluene, with the following amounts: $1-Y(0.59 \mathrm{~g}, 1.24 \mathrm{mmol})$, toluene $(20 \mathrm{ml})$ and ${ }^{n} \mathrm{BuLi}(1.6 \mathrm{M}$ in hexanes, $0.77 \mathrm{ml}, 1.24 \mathrm{mmol})$. 2-Y - toluene was isolated as colourless crystalline blocks $(0.37 \mathrm{~g}, 70 \%$ based on yttrium). Elemental analysis, found percentage (calculated percentage) for $\mathbf{2}-\mathrm{Y} \cdot$ toluene: $\mathrm{C}, 65.16(65.32) ; \mathrm{H}, 6.82(6.74) .{ }^{1} \mathrm{H}$ NMR (toluene- $\mathrm{D}_{8}, 298.15 \mathrm{~K}, \delta /$ p.p.m.): 6.78-6.93 (s, 6H, mesityl CH); 5.50-6.55 (s, 24H, $\mathrm{C}_{5} \mathrm{H}_{4} \mathrm{CH}_{3}$ ); 3.47-1.61 (s, overlapping peaks due to $\mathrm{CH}_{3}$ groups). ${ }^{31} \mathrm{P}$ NMR (benzene- $\mathrm{D}_{6}, 298.15 \mathrm{~K}, \delta /$ p.p.m.): $-124.28,-145.21$ and -142.65 .

[Li(thf $\left.)_{4}\right]_{2}\left[\left(C^{\prime}{ }_{2}{ }_{2} D y\right)_{3}(\mu-P M e s)_{3} L i\right] \cdot$ thf $\left(\left[L i(t h f)_{4}\right]_{2}[3-D y] \cdot\right.$ thf $)$. A solution of 2-Dy - toluene $(0.38 \mathrm{~g}, 0.25 \mathrm{mmol})$ in thf $(10 \mathrm{ml})$ was cooled to $-78^{\circ} \mathrm{C}$ and ${ }^{n} \mathrm{BuLi}$ $(1.6 \mathrm{M}$ in hexanes, $0.47 \mathrm{ml}, 75 \mathrm{mmol})$ was added drop wise. After stirring at $-78^{\circ} \mathrm{C}$ for $30 \mathrm{~min}$, the reaction was warmed to room temperature over $3 \mathrm{~h}$, after which time an orange colour had developed. The solution was concentrated until copious amounts of precipitate had formed, then the precipitate was re-dissolved by gentle heating and the solution stored at $+4^{\circ} \mathrm{C}$. $\left[\mathrm{Li}(\mathrm{thf})_{4}\right]_{2}[3-\mathrm{Dy}] \cdot$ thf formed as large orange blocks $(0.33 \mathrm{~g}, 64 \%)$. Elemental analysis, found percentage (calculated per \%) for $\left[\mathrm{Li}(\mathrm{thf})_{4}\right]_{2}[3-\mathrm{Dy}] \cdot$ thf: C, $56.88(57.10) ; \mathrm{H}, 7.25$ (7.12).

[Li(thf $\left.)_{4}\right]_{2}\left[\left(\mathrm{Cp}_{2}^{\prime}{ }_{2} \mathrm{Y}\right)_{3}(\mu \text {-PMes) })_{3} \mathrm{Li}\right] \cdot$ thf ([Li(thf $\left.)_{4}\right]_{2}[3-\mathrm{Y}] \cdot$ thf). The synthesis of $[3-\mathrm{Y}]\left[\mathrm{Li}(\mathrm{thf})_{4}\right]_{2} \cdot$ thf was accomplished using the procedure described above for $[3-Y]\left[\mathrm{Li}(\text { thf })_{4}\right]_{2}$. thf, with the following amounts: $2-\mathrm{Y} \cdot$ toluene $(0.34 \mathrm{~g}, 0.27 \mathrm{mmol})$, thf $(10 \mathrm{ml})$ and ${ }^{n} \mathrm{BuLi}(1.6 \mathrm{M}$ in hexanes, $0.50 \mathrm{ml}, 0.79 \mathrm{mmol})$. [ $\left.\mathrm{Li}(\mathrm{thf})_{4}\right]_{2}[3-\mathrm{Y}] \cdot$ thf was isolated as pale orange crystalline blocks $(0.27 \mathrm{~g}, 56 \%$ based on yttrium). Elemental analysis, found per \% (calculated per \%) for $[3-\mathrm{Y}]\left[\mathrm{Li}(\mathrm{thf})_{4}\right]_{2} \cdot$ thf: $\mathrm{C}$, 63.69 (63.77); $\mathrm{H}, 8.02$ (7.95). NMR spectra were acquired in dimethoxyethane (that is, $\left.\mathrm{C}_{4} \mathrm{H}_{10} \mathrm{O}_{2}\right)$ with a few drops of benzene- $\mathrm{D}_{6}$ for the signal lock. ${ }^{1} \mathrm{H}(298.15 \mathrm{~K}, \delta /$ p.p.m.): $6.78,6.68(2 \times \mathrm{s}, 2 \times 3 \mathrm{H}$, mesityl $\mathrm{CH}) ; 6.47,6.15,4.99$ and $4.74(\mathrm{~s}, 4 \times 6 \mathrm{H}$, $\left.\mathrm{C}_{5} \mathrm{H}_{4} \mathrm{CH}_{3}\right) ; 3.46\left(\mathrm{~m}, 4 \mathrm{H}\right.$, thf $\left.\mathrm{CH}_{2} \mathrm{OCH}_{2}\right) ; 2.59\left(\mathrm{~s}, 9 \mathrm{H}\right.$, ortho $\left.\mathrm{CH}_{3}\right) ; 2.52(\mathrm{~s}, 9 \mathrm{H}$, ortho $\left.\mathrm{CH}_{3}\right) ; 2.26$ (s, 9H, $\left.\mathrm{Cp}^{\prime} \mathrm{CH}_{3}\right) ; 2.08\left(\mathrm{~s}, 9 \mathrm{H}, \mathrm{Cp}^{\prime} \mathrm{CH}_{3}\right) ; 1.52\left(\mathrm{~m}, 4 \mathrm{H}\right.$, thf $\left.\mathrm{CH}_{2} \mathrm{CH}_{2} \mathrm{O}\right)$; $1.46\left(\mathrm{~s}, 9 \mathrm{H}\right.$, para $\left.\mathrm{CH}_{3}\right) .{ }^{31} \mathrm{P}$ NMR (benzene- $\mathrm{D}_{6}, 298.15 \mathrm{~K}, \delta /$ p.p.m.): +57.24 p.p.m.; a small amount of $\mathrm{Mes}_{2} \mathrm{PH}_{2}$ is observed at -157.51 p.p.m., which occurs due to the phosphinidene ligand reacting slowly with the DME solvent.

Doped sample (2-Y $\mathbf{2} \mathbf{D y}) /(\mathbf{2}-\mathbf{Y})$. The dilution experiment to obtain $\mathbf{2}-\mathbf{Y}_{\mathbf{2}} \mathbf{D y}$ doped into a matrix of 2-Y was achieved by combining 1-Dy $(0.0138 \mathrm{~g}$, $0.025 \mathrm{mmol})$ and $\mathbf{1}-\mathrm{Y}(0.2280 \mathrm{~g}, 0.475 \mathrm{mmol}$; that is, a 5:95 stoichiometric ratio $)$ as solids, and dissolving the mixture in toluene $(8 \mathrm{ml})$. Following the addition of ${ }^{n} \mathrm{BuLi}(1.6 \mathrm{M}, 0.31 \mathrm{ml}, 0.50 \mathrm{mmol})$ at $-78^{\circ} \mathrm{C}$ and a workup procedure as described for 2-Dy, the doped sample was obtained as colourless crystals $(0.088 \mathrm{~g}, 41 \%$ based on metal content)

Doped sample $\left.[\text { Li(thf })_{4}\right]_{2}\left[3-Y_{2} D y\right] \cdot$ thf $/\left[L i(\text { thf })_{4}\right]_{2}[3-Y] \cdot$ thf. The dilution experiment to obtain $\left[\mathrm{Li}(\mathrm{thf})_{4}\right]_{2}\left[3-\mathrm{Y}_{2} \mathrm{Dy}\right] \cdot$ thf doped into a matrix of $\left[\mathrm{Li}(\mathrm{thf})_{4}\right]_{2}$ [3-Y] - thf was achieved by the deprotonation of $2-\mathrm{Y}_{2} \mathrm{Dy}(0.14 \mathrm{~g}, 0.11 \mathrm{mmol})$ by of ${ }^{n} \mathrm{BuLi}(1.6 \mathrm{M}, 0.20 \mathrm{ml}, 0.32 \mathrm{mmol})$ at $-78^{\circ} \mathrm{C}$, with the workup procedure as described for $\left[\mathrm{Li}\left(\mathrm{thf}_{4}\right]_{2}[3-\mathrm{Dy}] \cdot\right.$ thf. The doped sample was obtained as pale orange crystals $(0.043 \mathrm{~g}, 22 \%$ based on metal content).

Characterization of doped materials. The two doped materials were characterized by X-ray diffraction (Supplementary Table 1): measurements of the unit cell parameters of several crystals of each were performed on an Oxford Xcaliber-2 diffractometer using $\mathrm{Mo}-\mathrm{K} \alpha$ radiation at $100 \mathrm{~K}$. The unit cell dimensions of both compounds were found to be equivalent (within $3 \sigma$ ) to those observed for their respective pure yttrium compounds $\mathbf{2}-\mathbf{Y}$ and $\left[\mathrm{Li}(\mathrm{thf})_{4}\right]_{2}[3-\mathbf{Y}] \cdot$ thf. Accurate dysprosium/yttrium ratios were measured by inductively coupled plasma atomic emission spectroscopy using a Thermo iCap 6300 ICP-OES instrument, which resulted in dysprosium contents of $5.0 \pm 0.5 \%$ for both doped materials.
Magnetic property measurements. The magnetic properties were measured using a Quantum Design MPMS-7 superconducting quantum interference device magnetometer at temperatures in the range of $1.8-300 \mathrm{~K}$. In a glove box, polycrystalline samples of each material were transferred to NMR tubes and restrained in eicosane. The NMR tubes were then placed under a partial vacuum and flame sealed before being transferred to the magnetometer.

Computational details. All calculations were done with MOLCAS 7.8 and are of CASSCF/RASSI/SINGLE_ANISO type. For each of 1-Dy, 2-Dy and 3-Dy, two computational models were employed. In model $\mathrm{A}$, all the $\mathrm{CH}_{3}$ groups were replaced by hydrogen atoms. Model B is the entire molecule as determined by X-ray crystallography, using all the atomic coordinates in the CIF files. The structures of model A (small) for 1-Dy, 2-Dy and 3-Dy are shown in Supplementary Figs 21-23, respectively. Two basis set approximations were used: $1-$ small (DZP quality), and 2-large (TZP quality). We have therefore considered four computational models for each magnetic centre in the investigated molecules: A1, A2, B1 and B2. The following results refer to the most complete model B2 (full structure with large basis set). Details of the calculations for models A1, A2 and B1 can be obtained from LFC. Each magnetic centre was computed, and neighbouring metal ions were computationally replaced by diamagnetic $\mathrm{Lu}^{3+}$. The active space of the CASSCF method includes the electrons from the last shell spanning the seven $4 \mathrm{f}$ orbitals of the $\mathrm{Ln}^{3+}$ ion. For all calculations, it was possible to mix only a limited number of roots, namely 21 sextets, 128 quartet and 130 doublet states. On the basis of the resulting spin-orbital multiplets, the SINGLE_ANISO programme computed the local magnetic properties ( $g$ tensors, main magnetic axes, local magnetic susceptibility, crystal-field parameters and so on). The ab initio results for the individual metal sites were used to compute the exchange spectrum and the magnetic properties of the trimetallic complexes using the POLY_ANISO program. The exchange interaction between the dysprosium sites is considered within the Lines model, while the contribution of the intramolecular dipole-dipole magnetic coupling is accounted for exactly given that all necessary data are available from the $a b$ initio calculations.

All three exchange interactions in 1-Dy and 2-Dy were described by one single Lines exchange parameter. The values of the Lines parameter for 1-Dy and 2-Dy was determined by minimizing the difference between the calculated and the measured magnetic susceptibility. The Lines parameters were expressed in terms of the Ising Hamiltonian by the expression $J_{\mathrm{ij}}^{\text {exch }}=25 J_{\text {Lines }} \cos \varphi_{\mathrm{ij}}$, where $\varphi_{\mathrm{ij}}$ is the angle between the main anisotropy axes $\left(z_{\mathrm{i}}\right.$ and $\left.z_{\mathrm{j}}\right)$ of the interacting sites. Supplementary Fig. 25 shows the comparison of the calculated and measured magnetic susceptibility.

\section{References}

1. Ishikawa, N., Sugita, M., Ishikawa, T., Koshihara, S. \& Kaizu, Y. Lanthanide double-decker complexes functioning as magnets at the single-molecular level. J. Am. Chem. Soc. 125, 8694-8695 (2003).

2. Ishikawa, N., Sugita, M. \& Wernsdorfer, W. Quantum tunnelling of magnetization in lanthanide single-molecule magnets: bis(phthalocyaninato)terbium and bis(phthalocyaninato). Angew. Chem. Int Ed. 44, 2931-2935 (2005).

3. Woodruff, D. N., Winpenny, R. E. P. \& Layfield, R. A. Lanthanide singlemolecule magnets. Chem. Rev. 113, 5110-5148 (2013).

4. Zhang, P., Guo, Y.-N. \& Tang, J. Recent advances in dysprosium-based singlemolecule magnets: structural overview and synthetic strategies. Coord. Chem. Rev. 257, 1728-1763 (2013).

5. Pedersen, K. S., Bendix, J. \& Clérac, R. Single-molecule magnet engineering: building block approaches. Chem. Commun. 50, 4396-4415 (2014).

6. Blagg, R. J. et al. Magnetic relaxation pathways in lanthanide single-molecule magnets. Nature Chem. 5, 673-678 (2013).

7. Ganivet, C. R. et al. Influence of peripheral substitution on the magnetic behaviour of single-ion magnets based on homo- and heteroleptic Tb ${ }^{\mathrm{III}}$ bis(phthalocyaninate). Chem. Eur. J. 19, 1457-1465 (2013).

8. Cornia, A., Mannini, M., Sainctavit, P. \& Sessoli, R. Chemical strategies and characterization tools for the organization of single molecule magnets on surfaces. Chem. Soc. Rev. 40, 3076-3091 (2011).

9. Thiele, S. et al. Electrically driven nuclear spin resonance in single-molecule magnets. Science 344, 1135-1138 (2014).

10. Vincent, R., Klyatskaya, S., Ruben, M., Wernsdorfer, W. \& Balestro, F. Electronic read-out of a single nuclear spin using a molecular spin transistor. Nature 488, 357-360 (2012).

11. Lodi Rizzini, A. et al. Exchange biasing single molecule magnets: coupling of $\mathrm{TbPc}_{2}$ to antiferromagnetic layers. Nano Lett. 12, 5703-5707 (2012).

12. Urdampilleta, M., Klyatskaya, S., Cleuziou, J.-P., Ruben, M. \& Wernsdorfer, W. Supramolecular spin valves. Nat. Mater. 10, 502-506 (2011).

13. AlDamen, M. A. et al. Mononuclear lanthanide single-molecule magnets based on the polyoxometalates $\left[\operatorname{Ln}\left(\mathrm{W}_{5} \mathrm{O}_{18}\right)_{2}\right]^{9-}$ and $\left[\operatorname{Ln}\left(\beta_{2}-\mathrm{SiW}_{11} \mathrm{O}_{39}\right)_{2}\right]^{13-}$ Inorg. Chem. 48, 3467-3479 (2009).

14. Ungur, L., Le Roy, J. J., Korobkov, I., Murugesu, M. \& Chibotaru, L. F. Fine-tuning the local symmetry to attain record blocking temperature and magnetic remanence in a single-ion magnet. Angew. Chem. Int. Ed. 53, 4413-4417 (2014). 
15. Meihaus, K. \& Long, J. R. Magnetic blocking at $10 \mathrm{~K}$ and a dipolar-mediated avalanche in salts of the bis $\left(\eta^{8}\right.$-cyclooctatetraenide) complex $\left[\operatorname{Er}(\mathrm{COT})_{2}\right]^{-}$. J. Am. Chem. Soc. 135, 17952-17957 (2013).

16. Perfetti, M. et al. Angular-resolved magnetometry beyond triclinic crystals part II: torque magnetometry of $\mathrm{Cp}^{*}$ ErCOT single-molecule magnets. Chem. Eur. J. 20, 14051-14056 (2014).

17. Layfield, R. A. Organometallic single-molecule magnets. Organometallics 33, 1084-1099 (2014).

18. Rinehart, J. D., Fang, M., Evans, W. J. \& Long, J. R. A N ${ }_{2}^{3-}$ radical-bridged terbium complex exhibiting magnetic hysteresis at 14 K. J. Am. Chem. Soc. 133, 14236-14239 (2011).

19. Li, T., Kaercher, S. \& Roesky, P. W. Synthesis, structure and reactivity of rareearth metal complexes containing anionic phosphorus ligands. Chem. Soc. Rev. 43, 42-57 (2014).

20. Masuda, J. D. et al. A lanthanide phosphinidene complex: synthesis, structure and phospha-Wittig reactivity. J. Am. Chem. Soc. 130, 2408-2409 (2008).

21. Wicker, B. F. et al. Phosphinidene complexes of scandium: powerful PAr group-transfer vehicles to organic and inorganic substrates. J. Am. Chem. Soc. 132, 3691-3693 (2010).

22. Lv, Y., Xu, X., Chen, Y., Leng, X. \& Borzov, M. V. Well-defined, soluble $\mathrm{P}^{3-}$-containing rare-earth metal compounds. Angew. Chem. Int. Ed. 50, 11227-11129 (2011).

23. Lv, Y. et al. Versatile reactivity of a four-coordinate scandium phosphinidene complex: reduction, addition, and $\mathrm{CO}$ activation reactions. J. Am. Chem. Soc. 135, 14784-14796 (2013).

24. Wang, K. et al. Homometallic rare-earth metal phosphinidene clusters: synthesis and reactivity. Angew. Chem. Int. Ed. 53, 1053-1056 (2014).

25. Cui, P., Chen, Y. \& Sun, J. An unprecedented lanthanide phosphinidene halide: synthesis, structure and reactivity. Chem. Commun. 43, 5547-5549 (2008).

26. Benelli, C. \& Gatteschi, D. Magnetism of lanthanides in molecular materials with transition-metal ions and organic radicals. Chem. Rev. 102, 2369-2387 (2002).

27. Habib, F. et al. The use of magnetic dilution to elucidate the slow magnetic relaxation effects of a Dy2 single-molecule magnet. J. Am. Chem. Soc. 133, 8830-8833 (2011)

28. Moreno Pineda, E. et al. Direct measurement of dysprosium(III) . . dysprosium(III) interactions in a single-molecule magnet. Nat. Commun. 5, 5243 (2014).

29. Aquilante, F. et al. MOLCAS 7: The Next Generation. J. Comput. Chem. 31, 224-247 (2010).

30. Chibotaru, L. F. \& Ungur, L. Ab initio calculation of anisotropic magnetic properties of complexes. I. Unique definition of pseudospin Hamiltonians and their derivation. J. Chem. Phys. 137, 064112 (2012).

31. Ungur, L. \& Chibotaru, L. F. Magnetic anisotropy in the excited states of low symmetry lanthanide complexes. Phys. Chem. Chem. Phys. 13, 20086-20090 (2011).

32. Feltham, H. L. C. et al. A Non-sandwiched macrocyclic monolanthanide singlemolecule magnet: the key role of axiality. Chem. Eur. J 17, 4362-4365 (2011).

33. Zhang, P. et al. Equatorially coordinated lanthanide single ion magnets. J. Am. Chem. Soc. 136, 4484-4487 (2014).

34. Demir, S., Zadrozny, J. M. \& Long, J. R. Large spin-relaxation barriers for the low-symmetry organolanthanide complexes $\left[\mathrm{Cp}^{*}{ }_{2} \operatorname{Ln}\left(\mathrm{BPh}_{4}\right)\right]$ $\left(\mathrm{Cp}^{*}=\right.$ pentamethylcyclopentadienyl; $\left.\mathrm{Ln}=\mathrm{Tb}, \mathrm{Dy}\right)$. Chem. Eur. J. 20, 9524-9529 (2014)

35. Tuna, F. et al. A high anisotropy barrier in a sulphur-bridged organodysprosium single-molecule magnet. Angew. Chem. Int. Ed. 51, 6976-6980 (2012).

36. Layfield, R. A. et al. Influence of the N-bridging ligand on magnetic relaxation in an organometallic dysprosium single-molecule magnet. Chem. Eur. J. 16, 4442-4446 (2010).

37. Chilton, N. F., Collison, D., McInnes, E. J. L., Winpenny, R. E. W. \& Soncini, A. An electrostatic model for the determination of magnetic anisotropy in dysprosium complexes. Nat. Commun. 4, 2551 (2013).
38. Guo, Y. N. et al. An NCN-pincer ligand dysprosium single-ion magnet showing magnetic relaxation via the second excited state. Sci. Rep. 4, 5471 (2014).

39. Gagliardi, L. \& Lindh, R. Karlström, Local properties of quantum chemical systems. J. Chem. Phys. 121, 4494-4500 (2004).

40. Ungur, L. \& Chibotaru, L. F. The computer programs Single_Aniso and Poly_Aniso (KU Leuven, 2007-2014).

41. Lines, M. E. Orbital angular momentum in the theory of paramagnetic clusters. J. Chem. Phys. 55, 2977-2984 (1971).

42. Vieru, V., Ungur, L. \& Chibotaru, L. F. Key role of frustration in suppression of magnetization blocking in single-molecule magnets. J. Phys. Chem. Lett. 4, 3565-3569 (2013).

43. Ungur, L., Van den Heuvel, W. \& Chibotaru, L. F. Ab initio investigation of non-collinear magnetic structure and lowest magnetic excitations in dysprosium triangles. New J. Chem. 33, 1224-1230 (2009).

44. Bartlett, R. A., Olmstead, M. M. \& Power, P. P. Synthesis and spectroscopic and $\mathrm{X}$-ray structural studies of the mesitylphosphines $\mathrm{PH}_{2} \mathrm{Mes}$ and $\mathrm{PHMes}_{2}$ $\left(\mathrm{Mes}=2,4,6-\mathrm{Me}_{3} \mathrm{C}_{6} \mathrm{H}_{2}\right)$ and Their Lithium Salts [Li(THF) $)_{3} \mathrm{PHMes}$ ] and [\{Li(OEt $\left.\left.\left.{ }_{2}\right) \mathrm{PMes}_{2}\right\}_{2}\right]$. Inorg. Chem. 26, 1941-1946 (1987).

45. Pugh, T., Kerridge, A. \& Layfield, R. A. Yttrium complexes of arsine, arsenide and arsinidene ligands. Angew. Chem. Int. Ed. 54, 4255-4258 (2015).

46. Wilkinson, G. \& Birmingham, J. M. Cyclopentadienyl compounds of Sc, Y, La Ce and some lanthanide elements. J. Am. Chem. Soc. 76, 6210-6210 (1954)

\section{Acknowledgements}

D.C., R.A.L., E.J.L.M. and T.P. thank the Engineering and Physical Science Research Council (EPSRC) for the award of responsive mode grant EP/K008722/1 and core capability grant EP/K039547/1. R.A.L. and L.F.C. thank The Royal Society for an International Exchange Grant. L.U. is a post-doc of the Fonds Wetenschappelijk Onderzoek-Vlaanderen, and also gratefully acknowledges INPAC and Methusalem grants of K.U. Leuven

\section{Author contributions}

R.A.L. conceived the experiments. Synthetic and crystallographic work was carried out by T.P., and T.P. and F.T. conducted the magnetic measurements. L.U. and L.F.C. carried out the theoretical analysis. T.P., L.U., D.C., E.J.L.M., L.F.C. and R.A.L. Analysed the experimental and theoretical data. R.A.L., L.U. and L.F.C. wrote the manuscript.

\section{Additional information}

Accession codes. The X-ray crystallographic coordinates for the structures reported in this Article have been deposited at the Cambridge Crystallographic Data Centre (CCDC) under deposition numbers 1032227-1032232. These data can be obtained free of charge from the Cambridge Crystallographic Data Centre via www.ccdc.cam.ac.uk/ data_request.cif.

Supplementary Information accompanies this paper at http://www.nature.com/ naturecommunications

Competing financial interests: The authors declare no competing financial interests

Reprints and permission information is available online at http://npg.nature.com/ reprintsandpermissions/

How to cite this article: Pugh, T. et al. Influencing the properties of dysprosium single-molecule magnets with phosphorus donor ligands. Nat. Commun. 6:7492 doi: $10.1038 /$ ncomms8492 (2015)

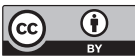

This work is licensed under a Creative Commons Attribution 4.0 International License. The images or other third party material in this article are included in the article's Creative Commons license, unless indicated otherwise in the credit line; if the material is not included under the Creative Commons license, users will need to obtain permission from the license holder to reproduce the material. To view a copy of this license, visit http://creativecommons.org/licenses/by/4.0/ 